Revista Brasileira de Informática na Educação - RBIE Brazilian Journal of Computers in Education (ISSN online: 2317-6121; print: 1414-5685) http://br-ie.org/pub/index.php/rbie

$\begin{array}{llll}\text { Submission: 07/Jul/2021; } & 1^{\text {st }} \text { round notif.: 10/Aug/2021; } & \text { New version: 12/Sep/2021; } & 2^{\text {nd }} \text { round notif.: 08/Oct/2021; } \\ \text { Camera ready: 15/Oct/2021; } & \text { Edition review: 19/Nov/2021; } & \text { Available online: 11/Dec/2021; } & \text { Published: 11/Dec/2021; }\end{array}$

\title{
Peer Instruction in Computing Higher Education: A Case Study of a Logic in Computer Science Course in Brazilian Context
}

\author{
Esdras L. Bispo Jr. \\ Federal University of Jataí (UFJ) \\ ORCID: 0000-0002-6373-6045 \\ bispojr@ufj.edu.br
}

\author{
Rosemara P. Lopes \\ Federal University of Goiás (UFG) \\ ORCID: 0000-0002-5498-2025 \\ rosemaralopes@gmail.com
}

Simone C. Santos

Federal University of Pernambuco (UFPE)

ORCID: 0000-0002-7903-9981

scs@cin.ufpe.br

\begin{abstract}
One of the challenges of Computing Education Research is the proposition of new learning methods. Researches indicate active learning methods are more effective than traditional ones. Peer Instruction is one of these learning methods that promotes a student-centered class, enabling (s)he constructs his/her comprehension through a structured approach with questions and peer discussions, used in Computing in the last years. Nevertheless, researches about the use of this method are very scarce in South America. Accordingly, this research aims to discuss the impact of Peer Instruction use on higher education from a Logic in Brazilian Computer Science course. The research context is an undergraduate course in Computer Science in the first term of 2018 at the Federal University of Jataí. Sufficient evidence was found for the veracity of two propositions related to this study: (i) Peer Instruction use guarantees a learning gain of students, and (ii) Peer Instruction is well accepted by students. Therefore, it concluded that Peer Instruction use is suitable for Logic courses in Computing Higher Education in Brazil, with good acceptance from students.
\end{abstract}

Keywords: Education; Computing; Logic; Peer Instruction; Brazil. 


\section{Introduction}

An excellent starting point to describe Computing Education Research (CER) is the junction of two areas: Education and Computing. Thus, it is possible to define the teaching and learning process improvement of Computing as a science among the main objectives of CER (Holmboe, McIver, \& George, 2001).

There are many open challenges in CER (Robins, 2015). One of them is the proposition of new teaching and learning methods (Fincher \& Petre, 2004). Several works point out active learning methods are more effective than traditional ones (Bonwell \& Eison, 1991; Grissom, 2013). It is possible to cite as active learning methods: (i) cooperative learning (Beck \& Chizhik, 2013), (ii) process-oriented guided inquiry learning (Moog \& Spencer, 2008), and (iii) peer instruction (PI). Other active approaches such as case-based learning (Srinivasan, Wilkes, Stevenson, Nguyen, \& Slavin, 2007), project-based learning (Bell, 2010), and problem-based learning (Savery, 2015) have much more connotation of teaching and learning "models" than active learning methods applicable to the classroom context. Therefore, these models can incorporate all the previously mentioned methods ((i)-(iii)).

PI is a teaching method that promotes a student-centered class to (s)he can construct his/her understanding through a structured approach from questions and peer discussions (Crouch \& Mazur, 2001). Although it was born in Physics courses, other courses like Biology (Smith, Wood, Krauter, \& Knight, 2011) use PI.

Several works discuss the impact of PI use in computing education (Chase \& Okie, 2000; Simon, Kohanfars, Lee, Tamayo, \& Cutts, 2010; Zingaro, 2010; Zingaro \& Porter, 2014; Lee, Garcia, \& Porter, 2013; Porter, Bailey Lee, \& Simon, 2013; Simon, Parris, \& Spacco, 2013; Johnson et al., 2016; Porter et al., 2016). One of PI's interesting directions in Computing Higher Education (CHE) is creating metrics to measure the learning quality (Smith et al., 2009; Porter, Bailey Lee, Simon, \& Zingaro, 2011). Questions like (i) "is there effective student learning in fact?" or (ii) "does student agree passively with your colleagues?" are addressed.

However, research about PI use is scarce in South America (Müller, Araujo, Veit, \& Schell, 2017). In this way, this work $^{1}$ aims to discuss the impact of PI use in CHE at Brazil from the teaching Logic in Computer Science (LCS). Two investigation questions northers this research: (i) "Why is PI use adequate for LCS courses in CHE in Brazil?"; and (ii) "How are the LCS students' impressions concerning PI?". This last question is crucial because it seems there is a resistance to active learning approaches by STEM ${ }^{2}$ students (Shekhar et al., 2015). The research context is the fresh students of the Computer Science program 2018 of the Federal University of Jataí.

The remains of this paper are divided as follows. Section 2 lists the main related works to this research. Section 3 presents important concepts about Education. Section 4 describes the PI methodology. Section 5 details some metrics used to assess the learning gains in PI. Section 6 delineates the research methodology used in this work. Section 7 presents the discussion of the case study results, listing the found pieces of evidence. And, finally, the final remarks and future

\footnotetext{
${ }^{1}$ This work is an extended version of the paper (Bispo Jr. \& Lopes, 2021) originally presented in the Brazilian Symposium of Computing Education (EduComp 2021).

${ }^{2}$ STEM stands for Science, Technology Engineering, and Mathematics.
} 
work (Section 8) are presented.

\section{Related Works}

In Computing Education, it used PI in many contexts. In higher school, Teixeira and Fontenele (2017) relate a didactic experience during teaching a Linear Algebra course teaching the matrix content in a Chemical Engineering program. In technical education, Oliveira et al. (2017) assess the PI efficacy considering fresh students' performance and engagement in introductory programming in an integrated high school-technical program in Informatics. Still, in technical education, Nogueira and Nogueira (2018) describe practices applied in an integrated high school-technical program in Computer Graphics, like tools and techniques used through PI use. Although none of these works investigates PI use in CHE.

In CHE in Brazil, there are investigations in various courses. In the Formal Languages course, Schechter and de Mendonça (2017) develop a methodology adaptation using PI and Justin-Time Teaching (JiTT) resources. In the Introductory Programming course, Chicon, Quaresma, and Garcês (2018) stimulate the immediate feedback of students from PI mediated by Socrative tool. At last, in the Human-Computer Interaction course, Gonçalves, Arpetti, and Baranauskas (2014) propose a model that aims to facilitate the social construction of meaning structured from PI, JiTT, and agile methods. However, none of these works investigates PI use in LCS courses.

Some works also investigate PI use in CHE from contexts outside South America. Chase and Okie (2000) compare a combination between PI and cooperative learning concerning the traditional approach. Porter et al. (2011) replicate the Smith et al. (2009) study by PI use, finding that students in upper-division computing courses also learn from peer discussions. Johnson et al. (2016) present a methodology for developing PI questions systematically for cybersecurity courses. All these paper investigates PI use from American contexts. However, the cut of this work is PI use in CHE in Brazil.

\section{Fundamentals in Education}

In this section, we will present some theoretical foundations in Education. Section 3.1 will delineate the traditional approach. And, in contrast, Section 3.2 will structure the theory of active learning.

\subsection{Traditional Approach}

To describe the traditional approach of the teaching and learning process is not an easy task. First, in most cases, this approach is referred to as an antagonistic (and sometimes negative) perspective to the other approaches, i.e., it serves as a reference to different approaches about "how does not conduct" the teaching and learning process.

And, secondly, as a consequence of the first justification, the adepts and the practitioners of this approach do not use to make this self-denomination (in the negative sense of "traditional" 
term). In the same way that the explicit differentiation about what is sacred and what is not sacred usually is made by the adepts of a certain religious group, the distinction between the traditional practice and other practices is established more commonly by discordant groups of traditional one.

Although there are difficulties in characterizing the traditional approach, it is necessary to do it. If there is a need to rethink the teacher's practice, it is required to identify which practice elements are pointing as challenges to be faced and overcome. Mizukami (1986) points out some important elements in this direction. Three are about the conception of (i) human beings, (ii) teacher-student relations, and (iii) assessment.

About the conception of human beings, the traditional approach usually assumes that their understanding of the world is a "clean slate" which to receive knowledge gradually acquired by the environment. This human being does not have an initial discernment about what is helpful to your learning, being fundamental the reception of this knowledge from the ancients one. The author says this human being "is a passive receptor until that, full of necessary pieces of information, (s)he can repeat them to others that do not possess them yet"3.

About the teacher-student relations, it usually assumes that the teacher has the knowledge possession which the student needs to learn. The teacher is responsible for establishing methodology, content, assessment, and interaction ways in the classroom. These aspects of the teachinglearning process are of total responsibility of the teacher, being the student disregard in this part of the process. Once the student is a passive receptor, the teacher's function is to transmit determined contents considered adequate to this one. The author says this is a "vertical relation, being that one of the polos (the teacher) detains the decisory power" 4 .

About the assessment conception, it typically considers the student's skill to reproduce the presented content by the professor in the classroom faithfully. The exam is the primary assessment instrument used by the professor, being a control instrument from which the students are reproved (or not) in a course or program. The author says the assessment, in this conception, "measures [...] the quantity and the accuracy of the information that [the student] can reproduce". In this perspective, the assessment is summative, applied at control points at the end of the exposure of specific content, as opposed to the formative assessment that allows the construction of learning procedurally, based on continuous feedback (Figuerêdo, dos Santos, Borba, \& Alexandre, 2011).

From this characterization, distinct conceptions about how should be the teaching-learning process were proposed as alternatives to the traditional approach. In opposition to the student conception as a "passive receptor", emerges the theory of active learning.

\subsection{Theory of Active Learning}

The theory of active learning emphasizes the need to engage students during their learning process. There is no clear definition of active learning, but some authors indirectly mention it as an inherent student activity in their writings. For instance, Dewey (2004, pp. 342) asserts "[...] learning means something which the individual does when he studies. It is an active, personally conducted affair".

\footnotetext{
${ }^{3}$ Original text in Portuguese: "é um receptor passivo até que, repleto das informações necessárias, pode repeti-las a outros que ainda não as possuem”. Os mais antigos também são os que determinam o que deve ser aprendido pelos seres noviços".

${ }^{4}$ Original text in Portuguese: "[relação] vertical, sendo que um dos polos (o professor) detém o poder decisório".
} 
Bonwell and Eison (1991, pp. 2) assert that learning is active when "greater emphasis is placed on students' exploration of their own attitudes and values".

It is necessary to highlight it is possible to have active learning even in an expository lesson. Although the student's environment significantly determines the conditions to her/his learning, it does not determine in a general way. In an expository lesson, the student can be active regarding each information and argument presented, reorganizing and filtering the received new information from the previous knowledge appropriated by her/him.

However, the role of an expository lesson in the formal education spaces is being rethought, bearing in mind these kinds of lessons are strongly linked to current conceptions of traditional teaching (inclusive in higher education). Some methodologies propose more effective student participation in the classroom to promote an environment that enhances active learning scenarios more concretely.

The teaching by discovery, for example, refers to a curriculum way that the students are exposed to specific questions and experiences so that they "discover for themselves the intended concepts [by the teacher]" (Hammer, 1997, pp. 489). This approach focuses efforts to integrate the need to attend to curriculum accomplishing expectations through the configuration of a favorable environment to an investigative inquiry of the students. The teaching by discovery adopts active learning and is an alternative to the traditional approach.

Despite the effort to present good results (Balım, 2009), there are difficulties with implanting the teaching by discovery. The tension between "to cover the content" and the scientific investigation is one of these difficulties (Hammer, 1995). Whereas the knowledge of the content is very required by the traditional approach, the teaching by discovery deposits more emphasis on developing necessary skills during the experimentation process of that content.

Faced with this scenario, researches in Psychology contributes to a better justification of active learning. One of these fields is Cognitive Psychology that is "the study of how people perceive, learn, remember, and think about information” (Sternberg \& Sternberg, 2012, pp. 3). In contrast to other Psychology areas, it looks to theorize more strongly about the functioning mechanism of cognitive structures of an individual. Other psychology areas can have more interest, for instance, in the behavioral aspects of individuals instead of the internal process of structuring assimilated information.

In this area, Ausubel (2000) proposes the assimilation theory of meaningful learning and retention or, as is known, the theory of meaningful learning (TML). TML asserts the learning of meaningful reception involves the acquisition of new knowledge from a presented learning material. However, it is presupposed that a set of essential elements for meaningful learning occurs beyond the existence of this material.

Some of these elements are better identified by describing the assimilation process in the meaningful learning phase. Three stages of this phase are important to TML. First is the selective anchoring of the learning material to existent ideas into the cognitive structure. Second is the interaction of new ideas introduced with the relevant ones already existing; the meaning of the new ideas emerges as a product of the interaction with the preexisting ideas. And, at last, third is the link in the memory (retention) of new emergent meanings with their correspondent anchoring ideas. 
From the conciliation between the expository lessons and the teaching by discovery as a purpose, the Peer Instruction methodology was proposed. This methodology looks to operationalize a practice that considers the traditional format of the classroom, alternating it with spaces that engage the students to construct their learning.

\section{Peer Instruction Methodology}

Prof. Eric Mazur from Harvard University originally proposed the Peer Instruction (PI) methodology. In a general way, PI looks to promote the learning with the focus on the inquiry, aiming the students to dedicate more time reflecting and discussing the content in the classroom instead of passively watching expository lessons of the teacher (Araujo \& Mazur, 2013). This proposal provides transformations for each element discussed in Section 3.1: the student's behavior as active actors in the learning process, the teacher-student relationship, and the assessment process.

PI arises from the found difficulties by Mazur in teaching Introductory Physics courses. Students, major part consisting of undergraduate ones from distinct courses of Physics, reported for him their course's frustrations. Even physics students, which were initially motivated to do the course, were dissatisfied with the course. Many of them came to transfer themselves to a different course.

Mazur reports that he was satisfied with your teaching, in a general way, and your students assessed him positively (Mazur, 1997). However, some papers, which he had read, point out no significant difference in the students' common sense concerning some physics concepts. As he did not believe that this was true in his context, he decided to apply a concept test inventory with his students.

To his surprise, his students (including physics ones) did not obtain satisfactory performance in the test. To Mazur, the conceptual test applied was simple and less complex than the exams he used to do. However, some of his students asked questions for him like: "Professor Mazur, how should I answer these questions? According to what was taught by you, or like I think?".

He realized that even though students had obtained a good performance in non-conceptual questions (e.g., formula application), they had not performed well in the conceptual test. Probably the conventional questions were measuring the student skill to reproduce a specified algorithm instead of the effective understanding of the presented concept in the classroom. The students were more focused on learning "recipes" or resolution strategies instead of understanding the physics concepts. In order to solve this problem, Mazur proposes a methodology that favors the students to understand the course concepts better. As follows, PI is presented in more detail.

The PI objectives are to explore the student interaction during the class and focus on subjacent concepts. Instead of using the class to present the material to be learned in the detailed level of the textbook, the classes mainly consist of short presentations of key topics. After these brief explanations, the students receive one conceptual question to answer and discuss in a group. This process (i) forces the students to think through their developed arguments and (ii) supplies for themselves the opportunity to assess their understanding of the concept.

PI consists of two moments: individual and group moments. The personal moment is based 
on the previous study of material available by the teacher to students. This moment is crucial for the proposed dynamic to reach its efficacy posteriorly. The purpose that is the group moment is better used with activities to potentialize the learning together with the colleagues and the teacher.

Thus, the previous study is the ideal moment for the student to have the first contact with the material, recognizing and developing part of the necessary knowledge. It is at this moment that arises eventual doubts, generating a major need of the student to understand the subject.

The group moment is a format reconfiguration of a classic class. The diagram (see Figure 1) illustrates how the process occurs. Each step of this process will be described in more detail as follows.

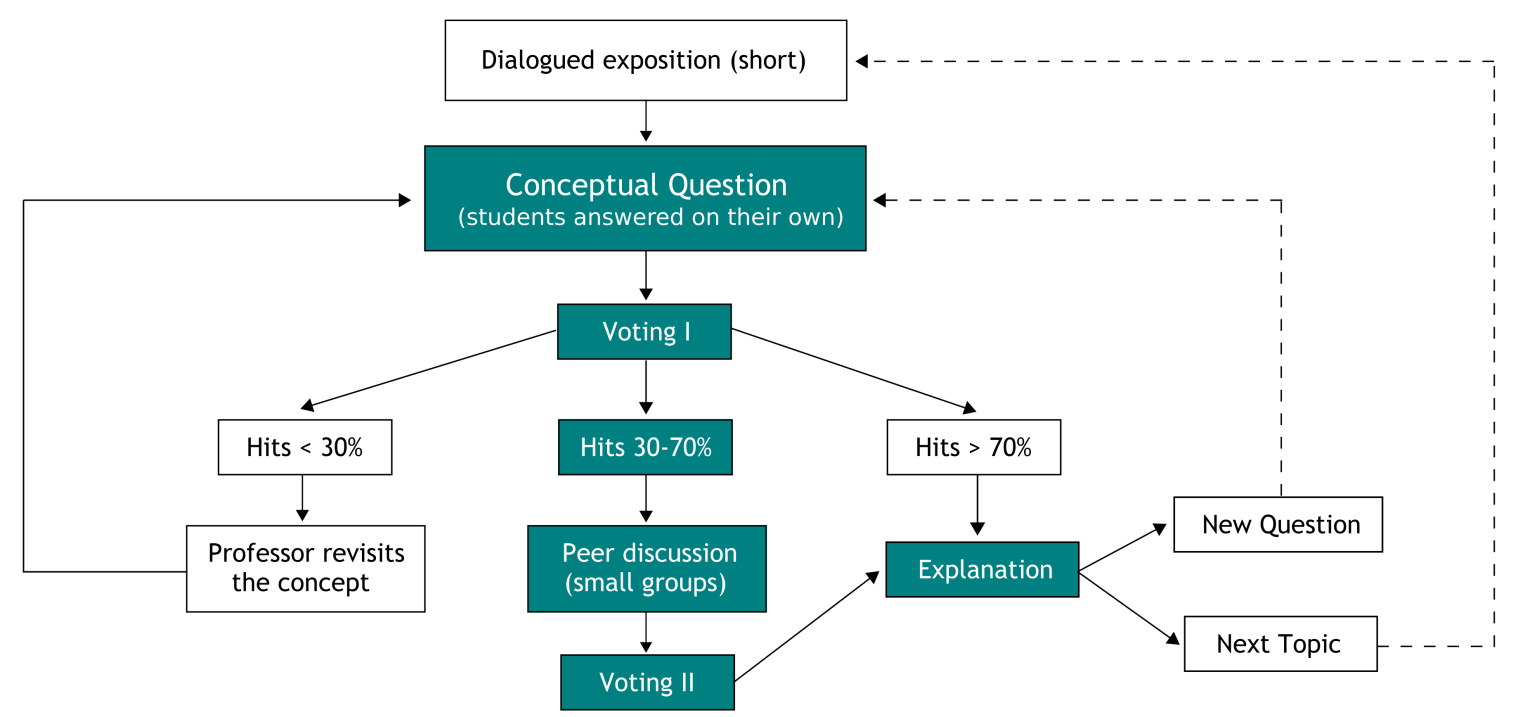

Figure 1: Diagram of the PI implementation process (adapted from ((Araujo \& Mazur, 2013, pp. 370)).

Each step of this process will be described in more detail as follows. The process begins with a dialogued exposition by the teacher. This dialogued exposition should be short with the only purpose to recap the material available to the students briefly. This step should not last more than 15 minutes.

The second step presents a conceptual question to the class. This question usually is multiplechoice. Each student should answer it individually. The conceptual question aims to promote and assess the student's understanding of the main important concepts chosen for that moment.

The third step carries out the recording of individual answers. When it chooses multiplechoice questions, it is possible to generate histograms of given responses by the students. From the hit percentage of the class referred to that conceptual question, the flux follows:

- if it is more than $70 \%$, it assumes the class satisfactorily understood the required concept. Hence, or it uses a new question involving the same concept, or it follows to the brief exposition of a new concept;

- if it is between $30 \%$ and $70 \%$, it assumes the part of the class satisfactorily understands the concept and can collaborate in the process of knowledge construction of your peers. It 
also supposes the discussion among the peers tests the supposed knowledge obtained by the part of the class that correctly answered the question. Thus it asks the students to divide themselves into groups and invest time to convince your peer about the reason to answer in this way;

- if it is less than $30 \%$, it assumes the class does not understand the required concept satisfactorily. Thus, the teacher revisits the concept, starting the process again.

At last, the fourth step comprehends the vote recording immediately after the discussion among the colleagues. This step only occurs if, in the first voting, the hit percentage situates between $30 \%$ and $70 \%$. It generates the new histogram, and the teacher finishes this phase by explaining the question and conceptual aspects. If still necessary to develop the current concept, a new question referred to one is presented. On the contrary, the next topic with new concepts is showed by dialogued exposition.

There are many variants of PI methodology. Some omit the voting in some steps. Others obligatorily carry out the peer discussions (independently of hit percentage recorded). However, the original suggestion proposed by Mazur (1997, pp. 10) is enumerated as follows:

1. Question posed ( $\cong 1$ minute);

2. Students given time to think ( $\cong 1$ minute);

3. Students record individual answers (optional);

4. Students convince their neighbors - peer instruction $(\cong 1-2$ minute);

5. Students record revised answers (optional);

6. Feedback of professor: tally of answers;

7. Explanation of correct answer $(\cong 2+$ minutes $)$.

\section{PI Metrics}

Various educational contexts used PI widely (Vickrey, Rosploch, Rahmanian, Pilarz, \& Stains, 2015). Thus arises the need to measure with better accuracy the PI efficacy in student learning. It will present the concept of isomorphic questions and two metrics used to measure the student's learning gain using PI.

\subsection{Isomorphic Questions}

One of the adopted strategies to answer some of the doubt about the PI efficacy is using isomorphic questions presented briefly by Smith et al. (2009). Isomorphic questions have "different stories" but require applying the same principles or concepts to reach the solution.

The Smith and colleagues' idea to use isomorphic questions in PI is a concept appropriation of problem isomorphs (Kotovsky, Hayes, \& Simon, 1985, pp. 251). The problem isomorphs can 
not be different in their structure. The differences between them reside in the personages, images, or models used in the problems. The proposal is to change the problem representation, preserving the domain structure of the task.

In this work, a pair of isomorphic questions is defined as $\left(q_{1}, q_{2}\right)$ where $q_{1}$ and $q_{2}$ are multiple-choice conceptual questions. $q_{1 a d}$ refers to representation of $q_{1}$ after peer discussion.

\subsection{Absolute Learning Gain}

On purpose to define the absolute learning gain and to provide better conditions to perform a transferability of this work (Merriam \& Tisdell, 2016, pp. 253), it presents the functions 1, 2, and 3:

$$
\operatorname{Hit}(x, q)= \begin{cases}1, & \text { if } x \text { hits } q, \\ 0, & \text { otherwise. }\end{cases}
$$

where $x$ is a student answering to question $q$;

$$
\operatorname{HitAverage}(q)=\frac{\sum_{x \in T} \operatorname{Hit}(x, q)}{n}
$$

where $T$ is a class of $n$ students; and

$$
\operatorname{AvgPercentage}_{\mathrm{Hit}}(Q)=\frac{\sum_{q \in Q} \operatorname{HitAverage}(q)}{m}
$$

where $Q$ is a set of $m$ questions.

Let be $I=\left\{\left(q_{1}^{1}, q_{2}^{1}\right) ;\left(q_{1}^{2}, q_{2}^{2}\right) ; \ldots ;\left(q_{1}^{m}, q_{2}^{m}\right)\right\}$ yet as the set of all pairs of isomorphic questions. Hence, $Q_{1}$ and $Q_{2}$ are defined from $I$, so that $Q_{1}=\left\{q_{1}^{1}, q_{1}^{2}, \ldots, q_{1}^{m}\right\}$ and $Q_{2}=\left\{q_{2}^{1}, q_{2}^{2}, \ldots, q_{2}^{m}\right\}$. Thus we define Absolute Learning Gain (ALG) as follows:

$$
A L G=\operatorname{AvgPercentage}_{\mathrm{Hit}}\left(Q_{2}\right)-\operatorname{AvgPercentage}_{\mathrm{Hit}}\left(Q_{1}\right)
$$

The subjacent idea of this metric is to measure the learning gain after a given intervention. Supposes a class obtained $51 \%$ of hits in the $Q_{1}$ set and, after the peer discussion, got $72 \%$ of hits in the $Q_{2}$ set. Hence, its ALG will be $21 \%$.

\subsection{Normalized Learning Gain}

The Normalized Learning Gain (NLG) (Hake, 1998, p. 3) measures how the student performance grows, comparing to the more extensive possible growth than (s)he can obtain. It computes NLG as follows:

$$
N L G=\frac{\text { AvgPercentage }_{\mathrm{Hit}}\left(Q_{2}\right)-\text { AvgPercentage }_{\mathrm{Hit}}\left(Q_{1}\right)}{100 \%-\operatorname{AvgPercentage}_{\mathrm{Hit}}\left(Q_{1}\right)}
$$


On given example in the previous section, while ALG will be $21 \%$, NLG will be $(72 \%-$ $51 \%) /(100 \%-51 \%) \cong 42.86 \%$. Thus, of the whole available learning gain, the intervention obtained approximately $42.86 \%$.

Another example can be more illustrative. Imagine two scenarios where ALG is $10 \%$ for two any class: $A$ and $B$. However, the $A$ class has AvgPercentage $\mathrm{Hit}_{\mathrm{t}}\left(Q_{1}\right)=20 \%$ and Avg Percentage $_{\mathrm{Hit}}\left(Q_{2}\right)=30 \%$, while $B$ class has AvgPercentage $\mathrm{Hit}_{\mathrm{Hit}}\left(Q_{1}\right)=80 \%$ and AvgPercentage $\mathrm{Hit}_{\mathrm{H}}$ $\left(Q_{2}\right)=90 \%$. Now, it should be more difficult to obtain an ALG of $10 \%$ when starts from $80 \%$ than when starts from $20 \%$. NLG has the objective to measure this relative difficult so that $A L G_{A}=12.5 \%$ and $A L G_{B}=50.0 \%$.

\subsection{Weighted Learning Gain}

In (Smith et al., 2009), a diagram with the average percentages of correct and incorrect answers given to conceptual questions was presented (Figure 2). The purpose of this diagram is helping to measure student learning gains when peer discussion occurs. The diagram is divided into three levels that match with the percentages referred to $Q_{1}, Q_{1 a d}$, and $Q_{2}$ sets.

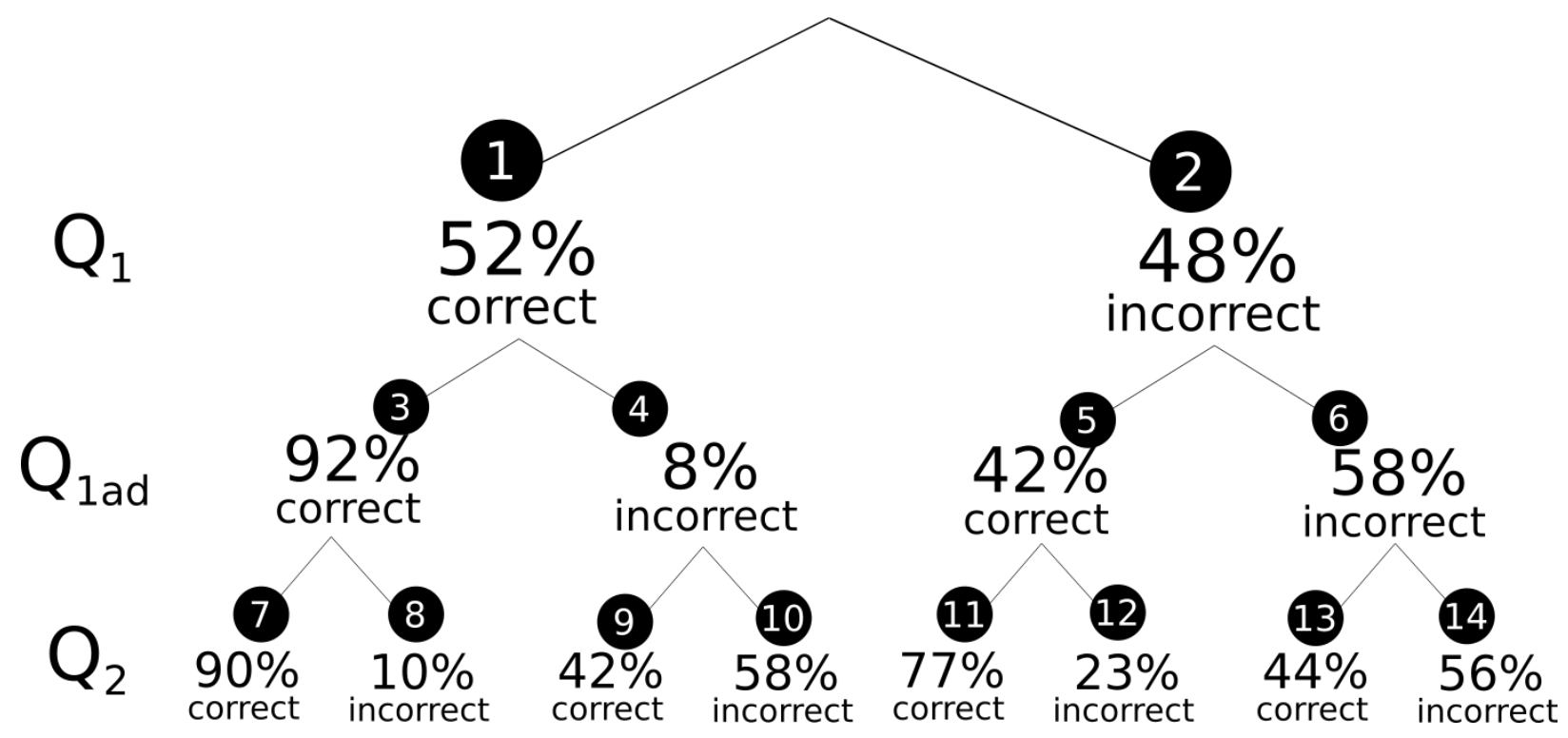

Figure 2: Diagram with the average percentages of correct and incorrect answers of $Q_{1}, Q_{1 a d}$ and $Q_{2}$ question set (Smith et al., 2009).

Nodes 1 and 2 of Figure 2 are percentages referred to answers of $Q_{1}$ set. Node 1 matches the average percentage of correct answers, while Node 2 matches the average percentage of incorrect answers.

Nodes 3 and 4 are percentages referred to answers of $Q_{1 a d}$ set, but only with the students that answered $q_{1}$ correctly (Node 1). Node 3 matches the average percentage of correct answers, while Node 4 matches the average percentage of incorrect answers. The sum of the percentages of Node 3 and 4 is $100 \%$ and matches the total value referred to Node 1.

This also happens in Nodes 5 and 6. These nodes are percentages referred to answers of $Q_{1 \text { ad }}$ set, but only with the students that answered $q_{1}$ incorrectly (Node 2). Node 5 matches the 
average percentage of incorrect answers. The sum of the percentages of Nodes 5 and 6 results $100 \%$ and matches the total value referred to Node 2. The same logic follows to other nodes of the Figure 2.

For Smith et al., some nodes of Figure 2 help to identify the learning gain in PI. For instance, Node 11 indicates a considerable learning gain. The students matched in this node are those that answered incorrectly $Q_{1}$ (Node 2) and, after peer discussion, answered correctly $Q_{1}$ (Node 5). Of these students, $77 \%$ responded $Q_{2}$ correctly, possibly indicating a positive effect of peer discussion in the learning process.

Porter et al. (2011) used PI in two Computer Science courses: Introduction of Theory of Computation and Computer Architecture. However, some expected results are not found. The percentage of Node 7 (see Figure 3) was slightly less than Node 3. And Node 11 has a median absolute value (53\%), besides having gain lesser than Node 5 .

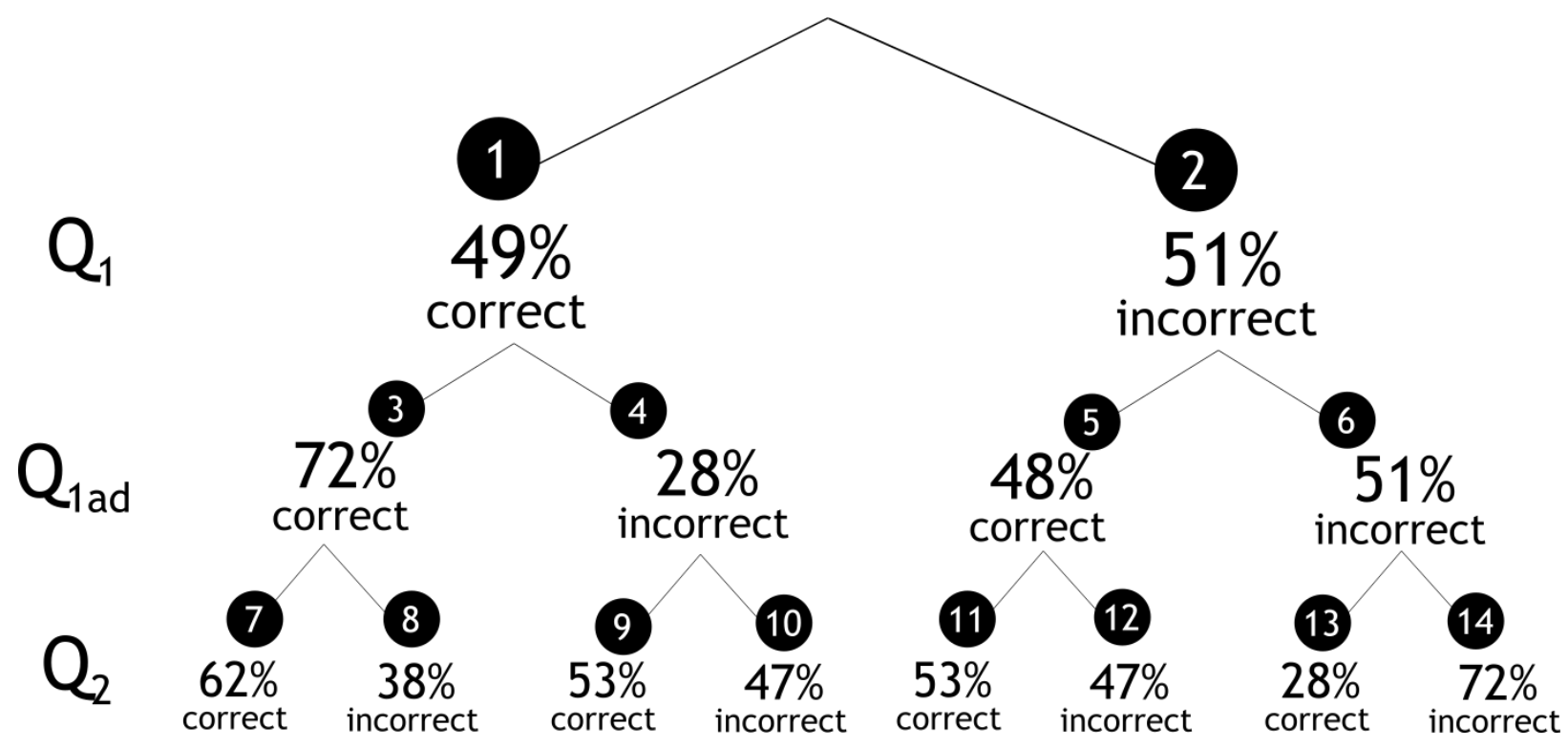

Figure 3: Diagram with the average percentages of correct and incorrect answers of Q1, Q1ad, and Q2 question set in Theory of Computation course (Porter et al., 2011).

Thus, they proposed an auxiliary understanding to complement the initial comprehension in (Smith et al., 2009). They propose two groups: a control group (CG) and a test group (TG) of potential learners. CG are those that answered both $q_{1}$ and $q_{1 a d}$ correctly (Node 3). TG are those that supposedly learned the concept through peer discussion (Node 5).

The idea is to use the CG skill to answer $q_{2}$ correctly to help in expectation normalization for TG answers $q_{2}$ correctly. Thus, if CG does not answer $Q_{2}$ satisfactorily, it should weigh the expectations concerning TG. In this way, it defines Weighted Learning Gain (WLG) as follows:

$$
W L G=\frac{\text { AvgPercentage }_{\mathrm{Hit}}(T G)}{\text { AvgPercentage }_{\mathrm{Hit}}(C G)}
$$

where AvgPercentage $\mathrm{Hit}_{\mathrm{H}}(T G)$ is the value of Node 11 and $\operatorname{AvgPercentag}_{\mathrm{Hit}_{\mathrm{H}}}(C G)$ is the value of Node 7 . Hence, in Figure $2, \mathrm{WLG}$ is $42 \% / 92 \% \cong 46 \%$, revealing the learning gain of TG was approximately $46 \%$ of the gain that CG obtained. 
The closer WLG is $100 \%$, the more meaningful is the learning gain obtained by TG. In principle, WLG should not reach values more than $100 \%$. However, it can not exclude this possibility in practice. Thus, once this occurs, it is necessary a more profound reflection about which scenarios and why CG obtained a learning gain lower than TG one.

\section{Methodology}

This work used case study as methodological approach. Yin (2003, pp. 13) defines case study as

"[...] an empirical inquiry that investigates a contemporary phenomenon within its real-life context, especially when the boundaries between phenomenon and context are not clearly evident".

Still, Yin (2003, pp. 14) continues characterizing the case study that:

"(i) copes with the technically distinctive situation in which there will be many more variables of interest than data point, and as one result; (ii) relies on multiple sources of evidence, with data needing to converge in a triangulation fashion, and as another result; (iii) benefits from the prior development of theoretical propositions to guide data collection and analysis".

\subsection{General Elements of the Case Study}

This is a holistic single-case study using an explanatory strategy. The study justification resides in the revelatory case of the PI use in CHE in Brazil from the teaching LCS course. The papers of bibliographical survey concentrate in countries of North America and Europa (Müller et al., 2017).

Two study questions are as follows. The first one (SQ.1) is "Why is PI use adequate for LCS courses in CHE in Brazil?". And the second one (SQ.2) is "How are the LCS students' impressions concerning PI?".

It investigates two propositions. The first one (P1) is "The PI use guarantees some learning gain of the students". The second one (P2) is "The students well receive PI". The SQ.1 answer depends directly on P1 and P2 will be confirmed, and the SQ.2 answer depends directly on the P2 investigation.

The analysis unit of this study is the Logic in CS course of the CS program of the Federal University of Jataí, situated in the southwest of Goiás. The course occurs in the first semester of 2018, with the participation of 44 students. Figure 4 presents the sociodemographic description of this analysis unit to provide better conditions to perform the transferability of this work (Merriam \& Tisdell, 2016, pp. 253). 


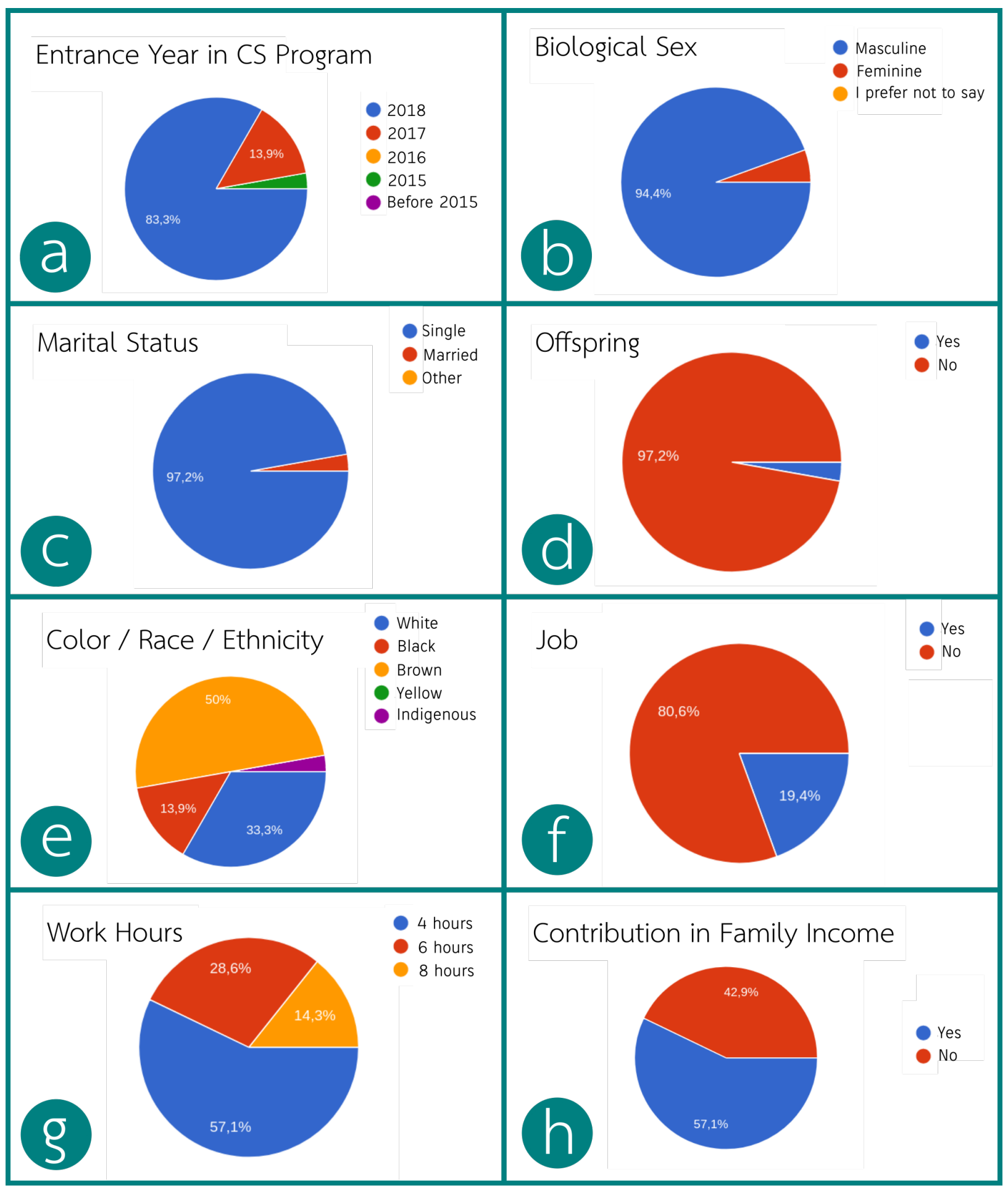

Figure 4: Pizza charts of the first questionnaire's percentage results about the sociodemographic data of the unit of analysis.

\subsection{Data Collection}

The collected data came from three sources: the answer recording performed by the students during classes (D1); and two questionnaires about the student impressions, being the first one 
with closed-ended questions (D2), and the second one with open-ended questions (D3).

The answers recording of the students occurs during the whole semester. It used QR code boards that match each student to your respective answers in each question. The Plickers platform ${ }^{5}$ mediated answer collection during the classes, computed the hit percent in real-time, and organized the responses in a spreadsheet for future analysis. It used 35 questions in total; among these, 06 pairs of isomorphic questions.

It adapted the first questionnaire about the students' impressions (Lee et al., 2013, p. 12:18) through closed-ended questions. Each question required a consent degree of the presented assertion, opting by one of five responses into a Liker scale (Nemoto \& Beglar, 2014), ranging from "Strongly disagree" until "Strongly agree". The assertions of the first questionnaire as follows as:

[QT1.1] The difficulty level of the course material, used in the previous study, was satisfactory for me.

[QT1.2] Thinking about clicker questions on my own, before discussing with people around me, helped me learn the course material.

[QT1.3] Discussing course topics with my seatmates in class helped me better understand the course material.

[QT1.4] The immediate feedback from clickers helped me focus on weaknesses in my understanding of the course material.

[QT1.5] QR code boards, used during voting, are an easy-to-use class collaboration tool.

[QT1.6] I recommend that other instructors use our approach (reading quizzes, clickers, in-class discussion) in their courses.

Beyond the assertion translation, there were only two adaptations concerning the original questionnaire. The first one was the modification of the [QT1.5] question, which instead of "clickers" was replaced by "QR code boards". The second one was the inclusion of the [QT1.1] question because there was a slight suspicion of the course's professor about the appropriateness (or not) of the course reading material.

The second questionnaire about the students' impressions, through open-ended questions, was adapted from (Mazur, 1997, p. 21). Its questions are listed as follows.

[QT2.1] What do you love about this class?

[QT2.2] What do you hate about this class?

[QT2.3] If you were teaching this class, what would you do?

[QT2.4] If you could change one thing about this class, what would it be?

[QT2.5] Is there more some commentary or observation to record concerning Peer Instruction?

\footnotetext{
${ }^{5}<$ http://www.plickers.com>
} 
Beyond the question translation, there was one adaptation concerning the original questionnaire. It included the [QT2.5] question to collect other eventual students' impressions that could arise. The students filled all two questionnaires after the ending of the semester, via an online tool.

\subsection{Data Analysis}

There is a binding between data and proposition were investigated. The D1 data supply support to the P1 proposition through of the ALG, NLG, and WLG metrics (see Section 5). The D2 and D3 data supply support to P1 and P2 propositions through the answers' triangulation of two questionnaires.

The discoveries' interpretation used three criteria. The first one $(\mathrm{C} 1)$ has quantitative nature and is satisfactory if: (I) ALG $\geq 10 \%$; (ii) $N L G \geq 20 \%$, e (iii) $W L G \geq 70 \%$. C1 directly matches P1.

The second criterion (C2) has qualitative-quantitative nature and contrasts, employing triangulation, the results of the two applied questionnaires. It proposes a representation index for the collected D2 answers, according defined as follows:

$$
\operatorname{Replnd}(P)=\frac{\sum_{x \in T} \operatorname{Answer}(x, P)}{n}
$$

where $\operatorname{Answer}(x, P)$ has values matches from 0 to 1 , in that (i) when $x$ answers $P$ with "Strongly disagree", the value is 0 , and (ii) when $x$ answers $P$ with "Strongly agree", the value is 1 . The other answers have values linearly proportional between these two values. The representation index indicates the average value of the class responses ( $n$ students) for a given question $P$ in D2. The class will tend to "strongly disagree" with the $P$ assertion, if the index tends to value 0 ; and will tend to "strongly agree", if the index tends to value 1.

Each answer in the D2 questionnaire was compared to the expressed impressions in free-text in D3. It is considered satisfactory if, for all questions in D2, your its representation index will be more than 70\%; and D3 results were coherent with D2 results. C2 directly matches $\mathrm{P} 1$ and $\mathrm{P} 2$. The third criterion (C3) has qualitative nature. It considers satisfactory if D3 presents backing evidence in collected data in D1 and D2. C3 directly matches P1 and P2.

Thus, attending to three criteria assumes the possibility of performing an analytic generalization (Kennedy, 1979), extending the study hypothesis to the proposed cut.

\section{Results}

It presents the discovered evidence from the analysis of collected data during the case study. We divided the evidence in order to sustain P1 (Section 7.1) and P2 (Section 7.2) propositions. We also present some methodological aspects as indirect issues to PI (Section 7.3) and threatens to results validity (Section 7.4). 


\subsection{Learning Gain (P1)}

P1 asserts the PI use guarantees a students' learning gain. We will bring investigation results of this assertion.

Piece of Evidence 1: ALG, NLG, and WLG confirm the learning gain.

From D1's data analysis, it confirms that the learning gain occurs through ALG, NLG, and WLG. In Figure 5, the chart presents the average percentages of correct answers of $Q_{1}, Q_{1 a d}$, and $Q_{2}$ sets. From this chart, it is possible to compute ALG and NLG values.

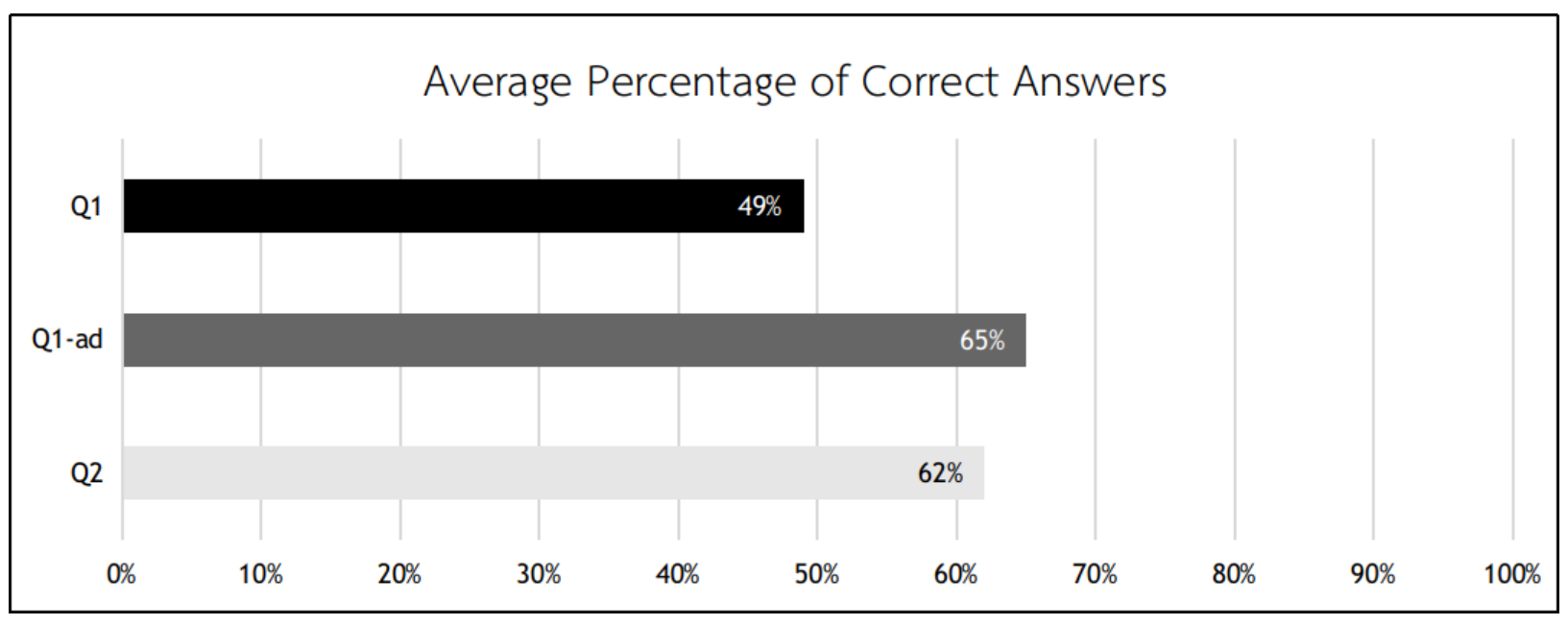

Figure 5: Chart with the average percentages of correct answers of $Q_{1}, Q_{1 a d}$, and $Q_{2}$ sets of Logic in CS course at the Federal University of Jataí.

According to $C_{1}$, ALG and NLG are satisfactory. ALG is $62 \%-49 \%=13 \%$, being more than $10 \%$. And NLG is $(62 \%-49 \%) /(100 \%-49 \%) \cong 25,50 \%$, being more than $20 \%$. Thus ALG closer to $10 \%$ is corresponding to the learning gain of nearly $25 \%$, referent to the whole possible gain. Hence there was a gain corresponding to more than a quarter of the maximum possible extent.

Still according to $C_{1}$, WLG is satisfactory too. Figure 6 summarizes the average percentages of correct and incorrect answers of the case. WLG is $51 \% / 71 \% \cong 71,83 \%$, being more than $70 \%$. Hence, TG reached a learning gain corresponding to nearly $72 \%$ of the obtained gain by CG.

Piece of Evidence 2: The students do not perform a "blind copy" of answers in peer discussion.

Smith et al. (2009) state this proposition from their proposed cut. The average percentages referring to $Q_{1 a d}$ and $Q_{2}$ set (see Piece of Evidence 1 ) are very close. It leads us to admit that the concept understanding does not occur simply by "blind copy" of the colleague's answer in peer discussion. If it were like that, it is possible the $Q_{2}$ values were closer to $Q_{1}$ (what is not true). The justification more plausible for these values is that there is an effective learning gain in the discussion step among the colleagues, given that $q_{1}$ and $q_{2}$ are isomorphic (i.e., are not equals). 


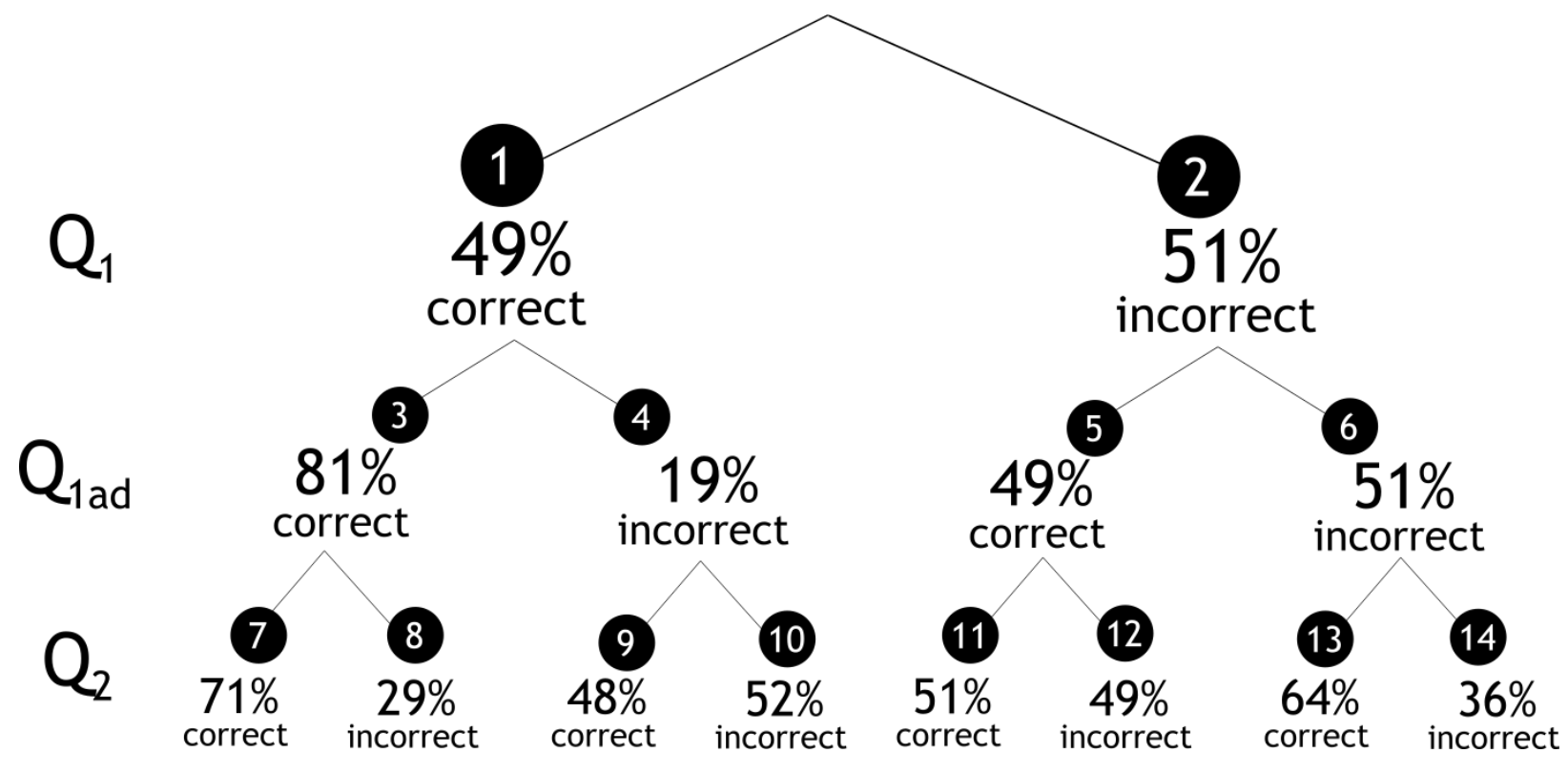

Figure 6: Diagram with the average percentages of correct and incorrect answers of $Q_{1}, Q_{1 a d}$ and $Q_{2}$ question set of Logic in CS course at the Federal University of Jataí .

The fact is, in percentages presented in Piece of Evidence 1, there is a dynamic equilibrium, such that those who correctly answer $Q_{1 a d}$ do not necessarily correctly answer $Q_{2}$ (see Figure 6). For instance, nearby $23,75 \%$ (Nodes 8 and 12) of those who correctly answered $Q_{1 a d}$, incorrectly answered $Q_{2}$, occurring a "negative flux". However, approximately 20,88\% (Nodes 9 and 13) of those who incorrectly answered $Q_{1 a d}$, correctly answered $Q_{2}$, occurring a "positive flux". Thus, the difference $20,88 \%-23,75 \% \cong-2,87 \%$ justifies the little difference between the average percentages of $Q_{2}$ and $Q_{1 a d}$, although the flux from one to another had been considerable.

Piece of Evidence 3: Peer discussion promotes a learning gain.

It verifies, from D3 data analysis, an indication that peer discussion promotes a learning gain. Socrates 6 states " $[. .$.$] that when we were talking about given answers, many times we had$ to convince (teach) the other colleagues and, in this way, the knowledge culminates fixing better in my head"7. This feedback kind was present in other students' answers, like in the Plato words: "The student interaction during the discussion facilitates the learning".

This interpretation matches with D2 data analysis about the students' impressions in quantitative terms, presented in Figure 7. The QT1.3 assertion states that "discussing course topics with my seatmates in class helped me better understand the course material". This assertion presents $67 \%$ of strong agreement with Replnd $(Q T 1.3)=88.89 \%$.

Piece of Evidence 4: The immediate feedback guarantees favorable conditions for learning occurs.

\footnotetext{
${ }^{6}$ To guarantee anonymity, we use fictitious names for the students.

${ }^{7}$ The students' perception was originated written in Portuguese. We translate it to English in this work.
} 


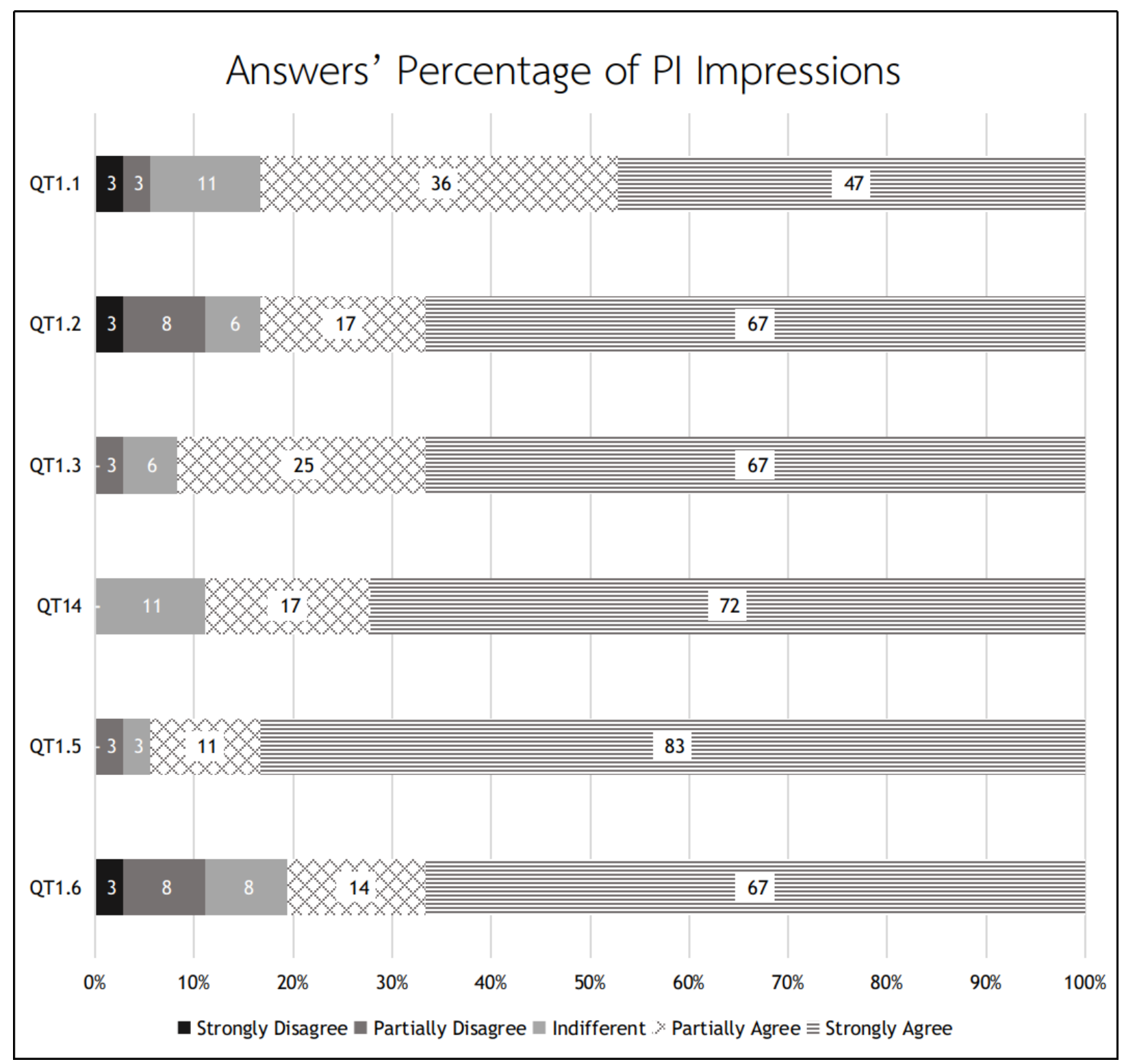

Figure 7: Chart of the first questionnaire's percentage results about the PI impressions divided by its six questions (QT1.1 to QT1.6) ranging the answers on Likert scale.

It verifies, from D3 data analysis, an indication that the immediate feedback guarantees favorable conditions for learning occurs. Aristotle states as follows:

"I can't see a more effective way to teach the course of Logic in CS. I directly and fastly see my error through the questions and answers by QR code. It simply was very important (for me, at least) to subject understanding".

This feedback kind too was present in other students' answers, like in Diogenes words: "[PI] stimulates the student to participate better in class, enabling to have better performance and already to know how your knowledge level is during course".

It found something interesting in Nichomacus words that state the need to work " [...] exercises with the students to diagnose the strong and weak points, for remedying them, like was 
made". The sensation is he realizes, at the same time, that PI performs a diagnosis assessment ("[...] like was made") and expresses the desire that this will be more explored in other learning spaces.

This interpretation matches with D2 data analysis presented in Figure 7. The QT1.4 assertion states that "the immediate feedback from clickers helped me focus on weaknesses in my understanding of the course material". This assertion presents $72 \%$ of strong agreement with $\operatorname{Replnd}(Q T 1.4)=90.28 \%$.

Piece of Evidence 5: The exposition to contradictory enables a validation in real-time of the supposed occurred learning.

It verifies, from D3 analysis data, an indication that this piece of evidence is true. Sophocles states that the "[...] fact to have diverse opinions of your classmate" was what he more liked in this class format.

However, the class presented an inadequate feeling of this PI step. To use the answers in the classroom as part of necessary punctuation to be approved (or reproved) does not seem to have been a good decision for this class. Aphrodite says:

"Sometimes, a good argumentation of a classmate can lead to a wrong answer, and assess the answers of given exercises in class can prejudice doubly someone that lost this class, or that need more time to absorbs the subject".

Thus, to perform the controlling assessment from PI question voting leads some students to believe that the exposition to contradictory can have negative consequences for the learning.

Still in this sense, Thales asserts that "the fact to hit in first tentative, but, clarifying the doubts with the classmates, to miss in second tentative" was what he more hated in PI. The exposition to contradictory should be a natural need of the learner, eager by the knowledge. However, the sensation still is the loss of punctuation, due to failing (incorrect answers), is received by students more as a punishment than as an evolution opportunity.

Piece of Evidence 6: The dynamicity of the approach positively contributes to the student's concentration in the classroom.

It verifies, from D3 data analysis, an indication that this assertion is true. Anaximander asserts that "the dynamicity does not allow the students easily get lost during the class and, consequently, the chance of success in studies and tests tend to increase for each them". Thus, to him, dynamicity contributes to one of the favorable elements for good learning.

Still in this direction, to be asked about what would change in this class format, Pythagoras says that "would look for a dynamic and non-monotonous way. I believe the traditional mode of the class does not fit for Logic". To him, the dynamic contributes to the class are not bored, which certainly favors in a positive way for students' concentration in the classroom. 
Although some realized the class as dynamic, Anaximenes records the lack of concentration of some. He says "sometimes, some classmates only joked or talked about random things during peer discussion". A way of resolution for this problem is the student rotation among the groups in each lesson. However, by and large, the strategy of student proximity was the chosen option.

Piece of Evidence 7: The PI structure brings gamification elements that involve the Computing students in the course.

The CS students, in a general way, like digital games. These lead the students to be more sympathetic to methodologies that include gamification elements. About what you would teach this course, Heraclitus asserts that it would be good to have "[...] gymkhanas among the groups about the Logic subject, works in groups with proposed themes by the professor! Lectures! Exams and exercises!".

Still in this sense, Parmenides says that it would be interesting a "competition in the number of hit questions with a prize for the three first positioned (a week of [free lunch in] University Restaurant], for example)". It is possible to extract the implicit association of gamification with dynamicity (Piece of Evidence 6) and the immersion in the referred activity.

There is the belief that gamification forces, maybe naturally, greater students' participation too. Plotinus says "I would try to add more disputes among the students to try forcing the discussion group to be taken more seriously". He may want to promote a favorable environment, according pointed by Anaximenes (Piece of Evidence 6).

It is true that the higher the necessary changes for the professor alters the class dynamic, the more the onus (s)he will have to pay concerning the class planning. The desire to become the class more dynamic, to promote a greater engagement with the knowledge discovery, is shared by professors and students. However, building a favorable academic environment for these changes can be viable in practice.

\subsection{PI Receptivity (P2)}

P2 states that the students well receive PI. As follows, we will bring the investigation results of this assertion.

Piece of Evidence 8: The students would indicate the approach for other professors.

It verifies, from D3 data analysis, an indication that this assertion is true. Democritus asserts that

"The method itself is amazing, and I agree that it should be used in more courses; therefore, it facilitates learning and leads to the homogeneity of the class knowledge base. The only part that brings insecurity is the psychological question of the assessment method.". 
According to the student points, the approach receptivity is positive, although the assessment method has been an insecure source. Probably this problem associates with the punctuation of the student answers during peer discussion (according to what is pointed in the Piece of Evidence 5).

This interpretation matches with D2 data analysis presented in Figure 7. The QT1.6 states that "I recommend that other instructors use our approach (reading quizzes, clickers, in-class discussion) in their courses". This assertion presents $67 \%$ of strong agreement with $\operatorname{Rep} \operatorname{lnd}(Q T 1.6)=$ $83.33 \%$.

\section{Piece of Evidence 9: The technology's use positively favored the approach approval.}

The technology's use positively favors in various directions. For PI, among other reasons, it is important for (i) to print a greater velocity in the attainment of immediate feedback for the students (Piece of Evidence 4), (ii) to promote a more favorable environment to students' concentration (Piece of Evidence 6), and (iii) to bring gamification elements that involve the students in the classroom (Piece of Evidence 7).

This interpretation matches with D2 data analysis presented in Figure 7. The QT1.5 assertion states that "QR code boards, used during voting, are an easy-to-use class collaboration tool". This assertion presents $83 \%$ of strong agreement with $\operatorname{Rep} \operatorname{lnd}(Q T 1.5)=93.75 \%$ (the greater index of the whole questionnaire).

In another direction, it verifies that the "recording of individual answers of the students", as a student said, is one of the approach problems. Although there is no clarity in the student report, it is possible your discomfort associates with the assessment problems cited in Pieces of Evidence 5 and 8.

Still, it registered by some students the lack of agility in QR code board delivery at the beginning of each class. Euclid says that "thinks the QR code board delivery can be more agile, but I can have an immediate suggestion". And Gorgias reinforces that "before the class beginning, the students should already have the board at hand".

At the beginning of each class, the delivery of the QR code board takes approximately 15 minutes. The classroom setting, together with board delivery, ranges from 20 to 30 minutes for each lesson. Each meeting takes one hour and a half. Although to be necessary to rethink this scenario to mitigate these discomforts, the adaptation costs of a usual classroom for PI compensate overall.

Piece of Evidence 10: There is a need for CS students to perform group work ${ }^{8}$.

There is an assertion, assumed as true concerning STEM students, about their sociability. It used to refer to these as retracted, introspective, and until few sociable. However, in answer to the question "If you were teaching this class, what would you do?" (QT2.3), some students'

\footnotetext{
${ }^{8}$ This piece of evidence was not presented in the original paper (Bispo Jr. \& Lopes, 2021) due to space restrictions.
} 
speech was opposite to this perception. Archimedes says that "[would give] more group activities, therefore they help in individual development". It is also interesting the Epicurus' words, as follow:

"Maybe would experiment with an exercise of group debates, using the logic to defend or refute arguments, but all in a more relaxed way, to increase the student interest in the course and to show some 'different' usefulness for the course".

This interpretation is coherent with the evidence about the importance of peer discussion (Piece of Evidence 3), the exposition to contradictory (Piece of Evidence 5), and the effective discussion exploitation (Piece of Evidence 2).

Piece of Evidence 11: The choice of the course material for the previous studies was satisfactory.

During the course teaching, It arose a suspect, by part of the professor, if the difficulty level of the proposed material was adequate (or not). Bearing this inquiry in mind, it included QT1.1 assertion to collect more specific data to investigate it better.

In this way, the QT1.1 assertion states that "the difficulty level of the course material, used in the previous study, was satisfactory for me". This assertion obtained near half of the class, indicating strong agreement (47\%, see Figure 7), with Replnd $(Q T 1.1)=80.56 \%$. It realizes that the difficulty of the proposed material was at a satisfactory level for the class.

Still in this direction, the QT1.2 assertion states that "thinking about clicker questions on my own, before discussing with people around me, helped me learn the course material". This assertion obtained much more of half the class, pointing strong agreement (67\%, see Figure 7), with Replnd $(Q T 1.2)=84.03 \%$. This indication indirectly reinforces that the choice of the proposed course material was adequate for the class, having a moment of meaningful learning during the individual voting step.

However, it identified in some students' reports the objection that "[...] the book is difficult to understand". Still, in this sense, Dionysius asserts that, if he would teach the course, "[...] would use a book with a better language to learn". The adopted book uses a median math formalism compared to other Logic books adopted in other institutions.

It is interesting to realize, yet concerning this point, what Athena declared. She says that "usually the solicited texts to be read were very confused. But, after the class, they became simpler to interpret". This indicates that the learning effectively occurred from the proposed course material, despite all mentioned reservations by the students.

The difficulty found by the students may arise from their formation's weaknesses during the pre-university period. The Leucippus declaration contributes to this reasoning:

"To participate in this methodology, the student needs to have a reasonable knowledge background, but not always everybody has. So it is necessary to pursue it, although not everybody knows how to do/get this background using the learning instruments are made, as the texts that we have to read for acquiring some knowledge, sometimes only 
it was possible to understand something when already have been spent 2-3 classes after the professor explained the given questions".

Piece of Evidence 12: There was positive feedback from the class concerning all steps of the PI cycle.

D2 data refers to all steps of the PI cycle. As it is possible to verify in Table 1, the representation index of all questions was superior to $80 \%$, such that the general average of these results was $86.81 \%$. In this way, it is possible to assert that the class positively reacted to this approach from these indicators.

\begin{tabular}{c|c|c|c|c|c|c|c}
\hline Question & QT1.1 & QT1.2 & QT1.3 & QT1.4 & QT1.5 & QT1.6 & Geral \\
\hline Replnd $(Q)$ & $80.56 \%$ & $84.03 \%$ & $88.89 \%$ & $90.28 \%$ & $93.75 \%$ & $83.33 \%$ & $86.81 \%$ \\
\hline
\end{tabular}

Table 1: Representation index of all questions of Questionnaire 1, including their general average.

Still in this direction, when asked for "what you would change, if you could, in the class format?" (QT2.4), there were various generic feedbacks like "I would do in the way that you do" or "there is no something that I don't like". This can reflect an uncritical thought about the process or maybe a good receptivity about the adopted approach (as points other pieces of evidence), or perhaps both. In front of other evidence and other students' reports before mentioned, it is more probable that there is a favorable disposition to the approach used.

It is important to note some students' reports about the non-fully adherence of the professor concerning the approach. The original proposal of PI admits a specific sequence. However, the professor left out the first explanation and did a direct question exposition to the students. The explanation was performed subsequently to after all voting moments. About how would teach the classes, Seneca says

"I would do the same, but too would shortly revise the content (5 minutes would be enough), asking some blatant or generalized doubt that could prejudice the performance during the class".

Augustine says too that would be interesting "a short explanation (resume) about the contents (for what they serve), raising the interest in the students for they research more deeply about the taught content [...]".

The original PI proposal (see Figure 1) expects the initial step of dialogued exposition in the cycle's beginning. The professor's choice concerning performing the repositioning of this step resided in intent to provoke the student to investigate the presented question more deeply. Once the voting occurred and the students receive the feedback of correct answers' percentage, a natural curiosity in the learner would arise to understand why that question would need to be better answered in a certain way instead of another one.

It is possible that this concern with the step inversion associates with the students' performance in terms of punctuation in the voting. The need becomes more imperative when (s)he can't have doubts before the question because this can prejudice the punctuation in assessment. 
This interpretation is coherent with the exposed about the answers' evaluation in the classroom in explaining the Pieces of Evidence 5, 8 and, 9.

Although evidence strongly points to the positive feedback of the class concerning PI, some students indicate resistance to active learning. Helen asserts that PI should not "[...] occupy the whole class. We learned all content outside the classroom, reading the texts". It seems, for Helen, the professor fulfills your function to teach more adequately, exposing the content instead of configuring the conditions appropriate for the learning occurs. Confirming this suspicion, Ulysses asserts that he realizes the "lack of the professor in the classroom" and Oedipus declares that "the dynamic occupies much time, since the organization. I would teach the content in class and would conduct this dynamic [in an] online [way]".

As an active methodology, PI is still seen (by some) as an interesting dynamic, but it is not the teaching in a strict sense. Although the general perception of PI use was well favorable, still is present this feeling in some. This is the result, probably, of the substantial paradigm shift that active methodologies impose on both the learner and the professor.

Apollo also mentions your apprehension about the activities' overload if other professors would adopt this strategy. He says that "in the case other professors would require the previous study of course material to watch the lessons, this would sums to college tasks and homework and would demand much time". Before a competitive scenario and much charge, the active learning can have some rejection, depending on the requirement level put on the students.

\subsection{Indirect Issues to PI}

Two indirect issues during PI use are important to be mentioned. These issues are presented as follows.

The first issue concerns the assessment criteria used during the course. As part of the control's assessment, 30\% of the score obtained by the students was originated from their given answers in the classroom, collected from PI voting. The voting before and after the discussion were scored, if correctly answered, with the same weight. If they hit all the PI questions in the classroom, they received the full score. Otherwise, the score was proportional to the number of hits.

If he would teach the course, Homer says he would change

"[...] the fact of the questions in the classroom to count many scores. Even if someone defends saying 'if it doesn't count point, the students don't pay attention', this is more difficult than until a test. So we have little time to the answers and don't have sufficient focus, resulting in the majority of classroom taken low scores in this area".

The explanation in Pieces of Evidence 5, 8, 9, and 12 mentions this assessment dissatisfaction of PI answers. It realizes, subsequently, that this choice does not adequate. As an alternative, a score could be established as a bonus to the final course grade or simply could remove any PI score like a component of the course grade.

The assessment issue goes beyond the PI use in the classroom. It evokes frustration and 
(until) rejection feelings, not contributing to a favorable environment to learning. Bacco has a declaration in this direction:

"Some classmates already commented, in talks about the class, that they felt frustrated and/or pressed. Even studying and knowing the subject, they didn't get the anticipated results due to insecurity or stress. However, this is not really a system failure, but it is the students' nature itself. Something that can help, in the first moment, is to 'comfort' the student in an environment that he is being exposed to, for he may stay comfortable with the use of the proposed material, unlike to be pressed by consequences of its use".

Another important issue was the need for the course professor to be subject to surgery. Due to this reality, the class organization during the semester was affected, and the number of weekly lessons increases from two to three ones.

In this sense, Tobias asserts that "would make available tho lesson by week" only. Cicero also says that "the teaching time [...] goes by so fast. Not ends to learn one and it has to learn another". Maybe the feeling of these students would be different if there is no professor removal by medical motives.

\subsection{Threatens to Results Validity}

It is important to note that the flux of isomorphic questions does not identically follow to conducted in (Porter et al., 2011). In the process performed by these authors, the $q_{2}$ individual voting is immediately performed after the $q_{1 a d}$ voting (after peer discussion). One of the purposes of this approach is to replicate more faithfully the methodological pathway presented in (Smith et al., 2009), aiming to guarantee a lesser professor influence in relative results to student learning gain.

This work followed the original PI flux, performing only the inversion of the dialogued expository step (see Piece of Evidence 12). Thus, after $q_{1 a d}$ individual voting, it performed the dialogued expository and presented $q_{2}$ after. The course professor adopted this methodological pathway by understanding to be more natural in students' inquiry process, promoting an immediate curiosity in the real moment that possible doubts are arising.

This register is important in eventual direct comparison among the results of this work and the obtained ones in (Porter et al., 2011). These reservations need to be made aiming to understand the involving context in the two projects adequately.

It is also important to mention that the evidence strength presented in this work can be better explored in future case studies. Causality relations from control groups can supply indications more solid to serve as support for presented propositions.

\section{Conclusions and Future Work}

This research aim was to discuss the impact of PI use in CHE in Brazil from the teaching LCS course. Two investigation questions northers this research. The first question was "Why is PI use adequate for LCS course in CHE in Brazil?". And the second one was "How are the LCS students' 
impressions concerning PI?". The research context was the 2018 entering class of CS program of the Federal University of Jataí.

It verified enough evidence to veracity of two propositions concerning the investigation questions. The first proposition is "The PI use guarantees some learning gain of the student". The second one is "The students well receive PI". It concludes that, from an analytic generalization perspective (Kennedy, 1979), PI is adequate for LCS course in CHE in Brazil, and students positively receive the approach in the classroom.

As mentioned in the discussion of the results (Section 7), one of the points of greater dissatisfaction by part of the students was issues related to the control's assessment. The use of voting answers in the classroom during PI as part of course grade does not well received by the students. It is necessary to observe these students' feedbacks since the verified positive effects in PI use could probably be more expressive.

As future work, the need to extend this study to other revelatory cases in Computing Education in South America arises. It also is interesting to note the percentage presented in Node 13 (Figure 6). Although the students had incorrectly answered both $q_{1}$ and $q_{1 a d}, 64 \%$ of them correctly answered $q_{2}$. It would be relevant to investigate it more deeply to identify the reasons for the occurrence of this fact.

\section{Acknowledgements}

This study was financed in part by the Coordenação de Aperfeiçoamento de Pessoal de Nível Superior - Brasil (CAPES) - Finance Code 001.

\section{Extended Awarded Article}

This publication is an extended version of an awarded paper at the Brazilian Symposium on Computing Education (EduComp 2021), entitled "Impacto do Uso da Peer Instruction no Ensino Superior de Lógica para Computação no Brasil”, DOI: 10.5753/educomp.2021.14473.

\section{References}

Araujo, I. S., \& Mazur, E. (2013). Instrução pelos colegas e ensino sob medida: uma proposta para o engajamento dos alunos no processo de ensino-aprendizagem de Física. Caderno Brasileiro de Ensino de Física, 30(2), 362-384. doi: 10.5007/2175-7941.2013v30n2p362 [GS Search]

Ausubel, D. P. (2000). Preview of assimilation theory of meaningful learning and retention. In The acquisition and retention of knowledge: A cognitive view (pp. 01-18). Springer Science $\&$ Business Media. doi: 10.1007/978-94-015-9454-7_1 [GS Search]

Balım, A. G. (2009). The effects of discovery learning on students' success and inquiry learning skills. Eurasian Journal of Educational Research (EJER)(35), 1-20. Retrieved from https:// 
app.trdizin.gov.tr/publication/paper/detail/T1RBMU5UQXc [GS Search]

Beck, L., \& Chizhik, A. (2013). Cooperative learning instructional methods for CS1: Design, implementation, and evaluation. ACM Transactions on Computing Education (TOCE), 13, 10. doi: $10.1145 / 2492686$ [GS Search]

Bell, S. (2010). Project-based learning for the 21st century: Skills for the future. The Clearing House: A Journal of Educational Strategies, Issues and Ideas, 83(2), 39-43. doi: 10.1080/00098650903505415 [GS Search]

Bispo Jr., E. L., \& Lopes, R. (2021). Impacto do Uso da Peer Instruction no Ensino Superior de Lógica para Computação no Brasil. In Anais do Simpósio Brasileiro de Educação em Computação (pp. 72-82). Porto Alegre, RS, Brasil: SBC. doi: 10.5753/educomp.2021.14473 [GS Search]

Bonwell, C. C., \& Eison, J. A. (1991). Active learning: Creating excitement in the classroom. ASHE-ERIC Higher Education Reports. Retrieved from https://eric.ed.gov/?id=ED336049 [GS Search]

Chase, J. D., \& Okie, E. G. (2000). Combining cooperative learning and peer instruction in introductory computer science. In ACM SIGCSE Bulletin (Vol. 32, pp. 372-376). doi: 10.1145/330908.331888 [GS Search]

Chicon, P. M. M., Quaresma, C. R. T., \& Garcês, S. B. B. (2018). Aplicação do método de ensino Peer Instruction para o ensino de lógica de programação com acadêmicos do curso de Ciência da Computação. In Anais do $5^{\circ}$ SENID . Retrieved from https://www.upf.br/ _uploads/Conteudo/senid/2018-artigos-completos/179081.pdf [GS Search]

Crouch, C. H., \& Mazur, E. (2001). Peer Instruction: Ten years of experience and results. American Journal of Physics, 69(9), 970-977. doi: 10.1119/1.1374249 [GS Search]

Dewey, J. (2004). Democracy and education. Courier Corporation. Retrieved from https:// www.journals.uchicago.edu/doi/abs/10.1086/453309 [GS Search]

Figuerêdo, C. d. O., dos Santos, S. C., Borba, P., \& Alexandre, G. (2011). Using PBL to develop software test engineers. In International conference on computers and advanced technology in education (pp. 305-322). doi: 10.2316/P.2011.734-029 [GS Search]

Fincher, S., \& Petre, M. (2004). Mapping the territory. Computer Science Education Research. Retrieved from https://kar.kent.ac.uk/14214/ [GS Search]

Gonçalves, F. M., Arpetti, A., \& Baranauskas, M. C. C. (2014). Facilitando a construção social de significado em sistemas de aprendizado colaborativo. In Proceedings of the XIX International Workshop on Educational Software, TISE (Vol. 10, pp. 318-326). Retrieved from http://www.tise.cl/volumen10/TISE2014/tise2014_submission_301.pdf [GS Search]

Grissom, S. (2013). Introduction to special issue on alternatives to lecture in the Computer Science classroom. ACM Transactions on Computing Education (TOCE), 13(3), 9. doi: 10.1145/2499947.2499948 [GS Search]

Hake, R. R. (1998). Interactive-engagement versus traditional methods: A six-thousand-student survey of mechanics test data for introductory Physics courses. American Journal of Physics, 66(1), 64-74. doi: 10.1119/1.18809 [GS Search]

Hammer, D. (1995). Student inquiry in a Physics class discussion. Cognition and Instruction, 13(3), 401-430. doi: 10.1207/s1532690xci1303_3 [GS Search]

Hammer, D. (1997). Discovery learning and discovery teaching. Cognition and instruction, 15(4), 485-529. doi: 10.1207/s1532690xci1504_2 [GS Search]

Holmboe, C., McIver, L., \& George, C. (2001). Research agenda for Computer Science Educa- 
tion. In 13th Workshop of the Psychology of Programming Interest Group (Vol. 207223). Retrieved from https://citeseerx.ist.psu.edu/viewdoc/download?doi=10.1.1.58.2776\&rep= rep1\&type=pdf [GS Search]

Johnson, W. E., Luzader, A., Ahmed, I., Roussev, V., Richard III, G. G., \& Lee, C. B. (2016). Development of Peer Instruction Questions for Cybersecurity Education. In 2016 USENIX Workshop on Advances in Security Education (ASE 16). Retrieved from https://www.usenix .org/conference/ase16/workshop-program/presentation/johnson [GS Search]

Kennedy, M. M. (1979). Generalizing from single case studies. Evaluation quarterly, 3(4), 661-678. doi: 10.1177/0193841X7900300409 [GS Search]

Kotovsky, K., Hayes, J. R., \& Simon, H. A. (1985). Why are some problems hard? Evidence from Tower of Hanoi. In Cognitive Psychology (Vol. 17, pp. 248-294). Elsevier. doi: 10.1016/0010-0285(85)90009-X [GS Search]

Lee, C. B., Garcia, S., \& Porter, L. (2013, August). Can peer instruction be effective in upper-division computer science courses? Trans. Comput. Educ., 13(3), 12:1-12:22. doi: 10.1145/2499947.2499949 [GS Search]

Mazur, E. (1997). Peer Instruction: a User's Manual. Upper Saddle River, NJ: Prentice Hall. Retrieved from https://www.google.com.br/books/edition/Peer_Instruction/ tjcbAQAAIAAJ [GS Search]

Merriam, S. B., \& Tisdell, E. J. (2016). Qualitative research: A guide to design and implementation (4th ed.).

Mizukami, M. d. G. N. (1986). Abordagem tradicional. In Ensino: as abordagens do processo (p. 7-18). Editora Pedagógica e Universitária (EPU). Retrieved from https://www.google .com.br/books/edition/Ensino/n3QQAAAAYAAJ [GS Search]

Moog, R. S., \& Spencer, J. N. (2008). POGIL: An Overview. In Process Oriented Guided Inquiry Learning (POGIL) (p. 1-13). doi: 10.1021/bk-2008-0994.ch001 [GS Search]

Müller, M. G., Araujo, I. S., Veit, E. A., \& Schell, J. (2017). Uma revisão da literatura acerca da implementação da metodologia interativa de ensino Peer Instruction (1991 a 2015). Revista Brasileira de Ensino de Física, 39(3). doi: 10.1590/1806-9126-RBEF-2017-0012 [GS Search]

Nemoto, T., \& Beglar, D. (2014). Developing Likert-scale questionnaires. In JALT 2013 Conference Proceedings (pp. 1-8). Retrieved from https://jalt-publications.org/sites/default/files/ pdf-article/jalt2013_001.pdf [GS Search]

Nogueira, K. d. F. C., \& Nogueira, K. L. (2018). Aplicação de metodologias ativas utilizando tecnologia educacional. In CEUR Workhop Proceedings (Vol. 2185, pp. 530-535). Retrieved from http://ceur-ws.org/Vol-2185/CtrlE_2018_paper_109.pdf [GS Search]

Oliveira, M. A. F., de Lima, J. V., do Canto Filho, A. B., Nunes, F. B., Lourega, L. V., \& Melo, J. N. B. (2017). Aplicação do método Peer Instruction no ensino de algoritmos e programação de computadores. RENOTE, 15(1). doi: 10.22456/1679-1916.75141 [GS Search]

Porter, L., Bailey Lee, C., \& Simon, B. (2013). Halving fail rates using Peer Instruction: a study of four Computer Science courses. In Proceeding of the 44th ACM Technical Symposium on Computer Science Education (pp. 177-182). doi: 10.1145/2445196.2445250 [GS Search]

Porter, L., Bailey Lee, C., Simon, B., \& Zingaro, D. (2011). Peer Instruction: do students really learn from peer discussion in computing? In Proceedings of the Seventh International Workshop on Computing Education Research (pp. 45-52). doi: 10.1145/2016911.2016923 [GS Search] 
Porter, L., Bouvier, D., Cutts, Q., Grissom, S., Lee, C., McCartney, R., ... Simon, B. (2016, May). A multi-institutional study of Peer Instruction in introductory computing. ACM Inroads, 7(2), 76-81. doi: 10.1145/2938142 [GS Search]

Robins, A. (2015). The ongoing challenges of Computer Science education research. Computer Science Education, 25(2), 115-119. doi: 10.1080/08993408.2015.1034350 [GS Search]

Savery, J. R. (2015). Overview of problem-based learning: Definitions and distinctions. Essential readings in problem-based learning: Exploring and extending the legacy of Howard $S$. Barrows, 9(2), 5-15. doi: 10.2307/j.ctt6wq6fh.6 [GS Search]

Schechter, L. M., \& de Mendonça, L. F. (2017). Uma aplicação da metodologia de "sala de aula invertida" no bacharelado em ciência da computação da UFRJ. Proceeding Series of the Brazilian Society of Computational and Applied Mathematics, 5(1). doi: 10.5540/03.2017.005.01.0561 [GS Search]

Shekhar, P., Demonbrun, M., Borrego, M., Finelli, C., Prince, M., Henderson, C., \& Waters, C. (2015). Development of an observation protocol to study undergraduate engineering student resistance to active learning. International Journal of Engineering Education, 31(2), 597-609. Retrieved from https://citeseerx.ist.psu.edu/viewdoc/download?doi=10.1.1.702 $.2980 \&$ rep $=$ rep $1 \&$ type $=$ pdf [GS Search]

Simon, B., Kohanfars, M., Lee, J., Tamayo, K., \& Cutts, Q. (2010). Experience report: Peer Instruction in introductory computing. In Proceedings of the 41st ACM Technical Symposium on Computer Science Education (pp. 341-345). doi: 10.1145/1734263.1734381 [GS Search]

Simon, B., Parris, J., \& Spacco, J. (2013). How We Teach Impacts Student Learning: Peer Instruction vs. Lecture in CS0. In Proceeding of the 44th ACM Technical Symposium on Computer Science Education (pp. 41-46). New York, NY, USA: ACM. doi: 10.1145/2445196.2445215 [GS Search]

Smith, M. K., Wood, W. B., Adams, W. K., Wieman, C., Knight, J. K., Guild, N., \& Su, T. T. (2009). Why peer discussion improves student performance on in-class concept questions. Science, 323(5910), 122-124. doi: 10.1126/science.1165919 [GS Search]

Smith, M. K., Wood, W. B., Krauter, K., \& Knight, J. K. (2011). Combining peer discussion with instructor explanation increases student learning from in-class concept questions. CBE_Life Sciences Education, 10(1), 55-63. doi: 10.1187/cbe.10-08-0101 [GS Search]

Srinivasan, M., Wilkes, M., Stevenson, F., Nguyen, T., \& Slavin, S. (2007). Comparing ProblemBased Learning with Case-Based Learning: effects of a major curricular shift at two institutions. Academic Medicine, 82(1), 74-82. doi: 10.1097/01.ACM.0000249963.93776.aa [GS Search]

Sternberg, R. J., \& Sternberg, K. (2012). Introduction to Cognitive Psychology. In Cognitive Psychology (7th ed., pp. 01-40). Cengage Learning. Retrieved from https://psycnet.apa.org/ record/1996-97250-000 [GS Search]

Teixeira, K. C. B., \& Fontenele, F. C. F. (2017). Metodologia Peer Instruction no ensino de matrizes: um relato de experiência na disciplina de Álgebra Linear. Educação Matemática em Revista - RS, 1(18). Retrieved from http://sbem.iuri0094.hospedagemdesites.ws/revista/ index.php/EMR-RS/article/view/1866 [GS Search]

Vickrey, T., Rosploch, K., Rahmanian, R., Pilarz, M., \& Stains, M. (2015). Research-based implementation of Peer Instruction: A literature review. CBE-Life Sciences Education, 14(1), es3. doi: 10.1187/cbe.14-11-0198 [GS Search] 
Yin, R. K. (2003). Case Study Research: Design and methods (3rd ed.). SAGE Publications. Retrieved from https://www.google.com.br/books/edition/Case_Study_Research/ BWea_9ZGQMwC [GS Search]

Zingaro, D. (2010). Experience Report: Peer Instruction in Remedial Computer Science. In EdMedia: World Conference on Educational Media and Technology (Vol. 2010, pp. 50305035). Retrieved from https://www.learntechlib.org/p/36184/ [GS Search]

Zingaro, D., \& Porter, L. (2014). Peer Instruction in Computing: The value of instructor intervention. Computers \& Education, 71, 87 - 96. doi: 10.1016/j.compedu.2013.09.015 [GS Search] 